73 DerSimonian R, Laird N. Meta-analysis in clinical trials. Controlled Clin Trial 1986;7:177-88

4 Petrie A. Lecture notes on medical statistics. Oxford: Blackwell Scientific Publications, 1978

75 Van Brummelen P, Koolen MI. Differences in sodium sensitivity in human hypertensives. Clin Invest Med 1987;10:581-5.

76 Anonymous. Salt and blood pressure: the next chapter [Editorial]. Lancet $1989 ; \mathrm{i}: 1301-3$

77 MacMahon S, Peto R, Cutler J, et al. Blood pressure, stroke, and coronary heart disease. Part l, proionged differences in blood pressure: prospective hervational studies corrected for the regression dilution hias. Lancel 1990;335:765-74.

78 Collins R, Peto R, MacMahon S, et al. Blood pressure, stroke and coronary heart disease. Part 2 , short-cerm reductions in blowd pressure: overving Ceart disease. Part 2, short-lerm reductions in hlood pressure: overvew $827-38$
79 Rutan GH, McDonald RH, Kuller LH. A historical perspective of elevated systolic vs. diastolic blood pressure from an epidemiological and clinical trials viewpoint. F Clin Epidemiol 1989;42:663-73.

80 British Hypertension Society Working Party. Treating mild hypertension. BMF 1989;298:694-8.

81 Bucknall CA, Morris GK, Mitchell JRA. Physicians' attitudes to four common problems: hypertension, atrial fibrillation, transient ischaemic attacks and angina pectoris. $B M 7$ 1986;293:739-42.

82 James WPT, Ralph A, Sanche\%-Castillo CP. The dominance of salt in manufactured food in the sodium intake of affluent societies. Lancet 1987;i:426-9.

\title{
Mortality, neoplasia, and Creutzfeldt-Jakob disease in patients treated with human pituitary growth hormone in the United Kingdom
}

\author{
C R Buchanan, M A Preece, R D G Milner
}

\section{Abstract}

Objective-To determine the cause of death and incidence of neoplasia in patients treated with human pituitary growth hormone.

Design-A long term cohort study established to receive details of death certification and tumour registrations through the Office of Population Censuses and Surveys and NHS central register.

Patients-All patients (1246 male, 662 female) treated for short stature with pituitary growth hormone under the Medical Research Council working party and health services human growth hormone committee.

Main outcome measures-Death or development of neoplasia.

Results -110 patients died (68 male, 42 female; aged 0.9-57 years) from 1972 to 1990 . Fifty three deaths were from neoplasia responsible for growth hormone deficiency (27 craniopharyngioma, 24 other intracranial tumour, two leukaemia); two from histiocytosis $X$; and 13 from pituitary insufficiency. Six patients died of Creutzfeldt-Jakob disease, six of other neurological disorders, and eight of acute infection. Other deaths were apparently unrelated to growth hormone deficiency or its treatment. Seventeen tumours (in 16 patients) were identified during or after growth hormone treatment. Four were in patients with previous intracranial neoplasia and two were after cranial irradiation. Thirteen were intracranial, the others being Hodgkin's lymphoma, osteosarcoma, carcinoma of colon, and basal cell carcinoma.

Conclusions - Recurrence or progression of intracranial tumours and potentially avoidable metabolic consequences of hypopituitarism were the main causes of death. Growth hormone treatment probably did not contribute to new tumour development. Creutzfeldt-Jakob disease after pituitary growth hormone treatment continues to occur in the United Kingdom. This cohort must remain under long term review.

\section{Introduction}

Treatment of short stature with human pituitary growth hormone was first described in $1958 .{ }^{1}$ A similar preparation was introduced in the United Kingdom under a Medical Research Council working party in 1959, and from 1977 pituitary growth hormone was available through the Health Services Human Growth Hormone Committee. ${ }^{2}$ By 1985 over 850 patients in the
United Kingdom and Eire were receiving growth hormone, and its use for causes of short stature other than classical growth hormone deficiency was under reassessment. ${ }^{3}$ The only adverse effect of this treatment then known was the occurrence of growth hormone antibodies, which rarely inhibited the response. ${ }^{24}$

In 1985 pituitary growth hormone treatment became associated with fatal Creutzfeldt-Jakob disease, including one case in the United Kingdom, ${ }^{5-8}$ and such preparations were withdrawn almost world wide. Our study was then instigated to review mortality and monitor prospectively the long term health of patients in the United Kingdom treated with growth hormone. We report the mortality and cancer registration data from 1959 to December 1990.

\section{Patients and methods}

Patients treated with growth hormone from 1959 to 1985 in the United Kingdom and Eire were identified from Health Services Human Growth Hormone Committee records. These were collated with the NHS central register and registrar's offices in Scotland and Northern Ireland to ascertain deaths and cancer registrations and "flag" survivors so that future deaths and cancer registrations could be notified. In addition, deaths from Creutzfeldt-Jakob disease and similar neurological disorders from 1971 to 1984 were reviewed; none of these patients had been treated with growth hormone. About 40 patients from the United Kingdom received commercial growth hormone preparations and were excluded from the study, as were patients who received only recombinant growth hormone. ${ }^{15}$

Cause of death was determined from death certificates, case notes, and discussion with doctors caring for the patients. Information from necropsy was available in 44 cases. Comparison between groups was by $\chi^{2}$ or unpaired Student's $t$ test, with significance at the 5\% level.

\section{Results}

Overall, 1908 patients were registered as having received pituitary growth hormone (fig 1). Treatment started at ages from 1 month (congenital hypopituitarism) to 55 years (idiopathic hypopituitarism). Figure 2 shows their distribution by year of birth, and table I shows diagnoses when treatment started. Patients deficient in two or more anterior pituitary
Correspondence to:

BM7 1991;302:824-8 
FIG $1-C u m u l a t i v e$ yearly totals of the number of patients treated with human pituitary growth hormone (line) and the number of deaths (bars)
FIG 2-Number of patients treated with human pituitary growth hormone by year of birth

FIG 3-Number of deaths after treatment with human pituitary growth hormone by age at death hormones were designated "panhypopituitary." Follow up data were insufficient to reclassify patients according to evolution of disease-for example, from isolated growth hormone deficiency to panhypopituitarism. Such revision would have been limited
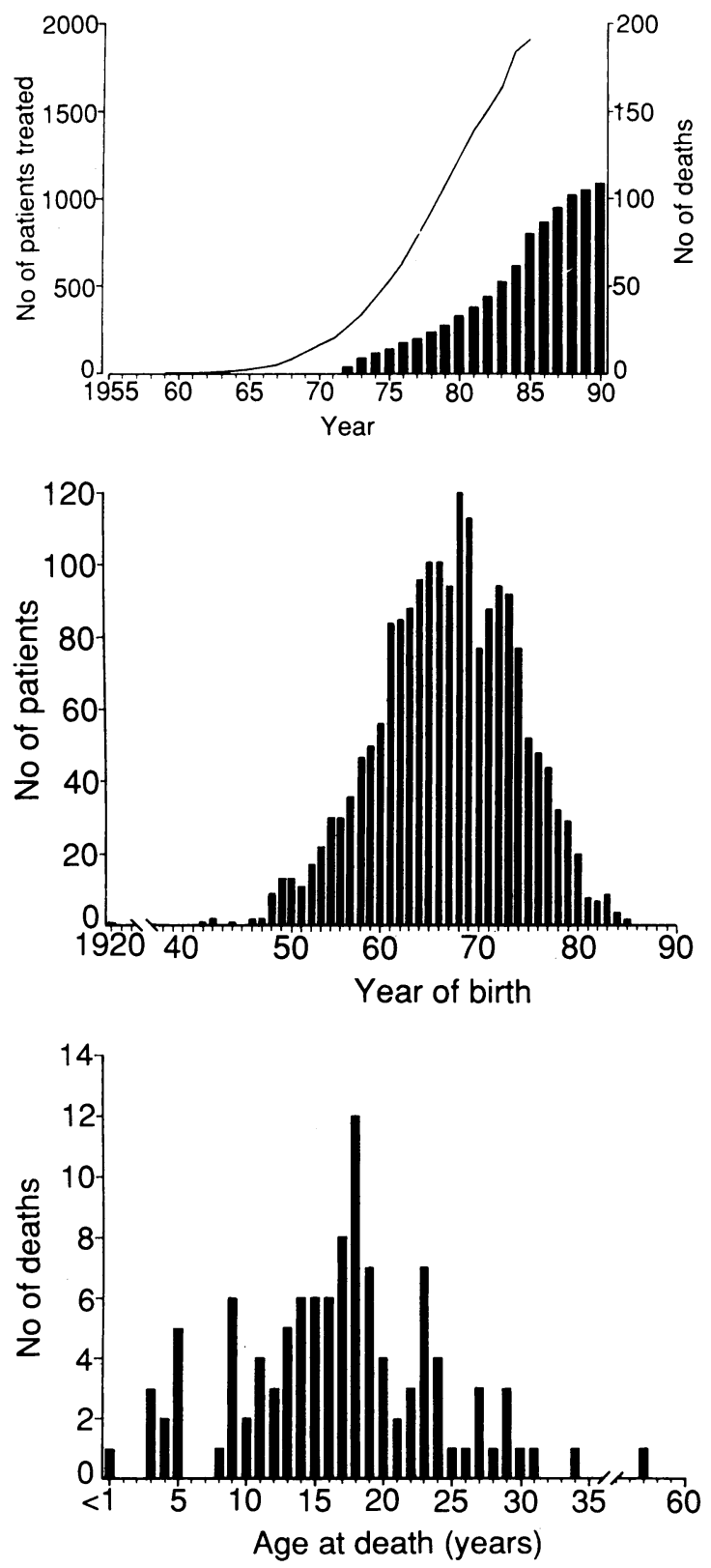

TABLE II-Causes of death after treatment with human pituitary growth hormone

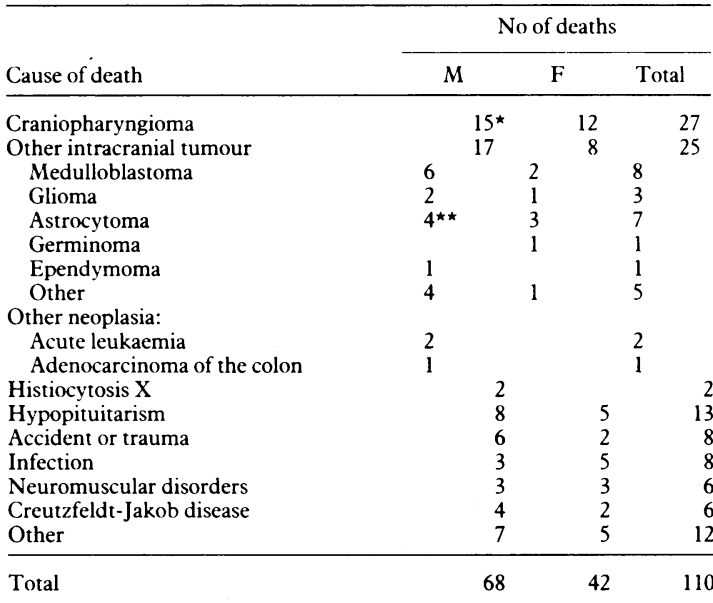

*, $\star \star$ Include one death each from astrocytoma arising after crania irradiation for craniopharyngioma $\left(^{\star}\right)$ or acute lymphoblastic leukaemia $(\star \star)$.

mainly to a small proportion of patients considered initially to have isolated growth hormone deficiency. The category "other" applies mainly to those treated when growth hormone treatment for short stature was first evaluated. ${ }^{216}$ Treatment was for a one year assessment period then, when appropriate, until stature was satisfactory or growth complete. The weekly dose ranged from 10 to $20 \mathrm{IU}$, given in two or three injections. ${ }^{2}$

The status of 1810 patients is known, but it is unconfirmed for 98 patients, including 28 in Ireland These untraced patients are representative of the cohort. If they had remained in the United Kingdom death or the occurrence of cancer would probably have been reported. For statistical purposes they are assumed to be alive.

There were 110 deaths (fig 1). Mean age at death was $17 \cdot 0$ years (SD 7.9) (fig 3 ) compared with their mean age when starting treatment of 11.3 years (SD 6.2; range $0 \cdot 5-53$ ).

\section{NEOPLASIA}

Death resulted from the cause of growth hormone deficiency in 55 cases, most from recurrence or complications of intracranial tumours (table II). Four deaths were from intracranial tumours not apparent when treatment started, two developing within an irradiation field. Table III shows the tumours identified after starting growth hormone treatment.

TABLE I - Indications for treatment with pituitary growth hormone of 1908 patients and number of deaths in each diagnostic category

\begin{tabular}{|c|c|c|c|c|c|c|c|c|c|c|c|c|}
\hline \multirow[b]{2}{*}{ Diagnosis } & \multicolumn{3}{|c|}{ No treated } & \multicolumn{4}{|c|}{ No of deaths } & \multicolumn{5}{|c|}{ No untraced } \\
\hline & $M$ & $\mathrm{~F}$ & Total & M & $\mathbf{F}$ & & Total & $M$ & & & To & \\
\hline Idiopathic isolated growth hormone deficiency & 734 & 270 & 1004 & 1 & & 3 & 15 & & & 15 & & 55 \\
\hline Idiopathic panhypopituitarism & 125 & 63 & 188 & 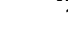 & & 1 & 8 & & & 3 & & 6 \\
\hline Craniopharyngioma & 126 & 104 & 230 & 2 & & 15 & 35 & & & 7 & & 16 \\
\hline Other intracranial tumour & 109 & 85 & 194 & 1 & & 13 & 32 & & & 1 & & 10 \\
\hline Medulloblastoma & 30 & 21 & 51 & 6 & 4 & & 10 & 3 & & & 3 & \\
\hline Glioma & 11 & 16 & 27 & 3 & 2 & & 5 & & & & & \\
\hline Astrocytoma & 11 & 5 & 16 & 2 & 2 & & 4 & 1 & & & 1 & \\
\hline Germinoma & 9 & 11 & 20 & & 2 & & 2 & 1 & & & 1 & \\
\hline Ependymona & 8 & 5 & 13 & 2 & & & 2 & 1 & & & 1 & \\
\hline Chromophobe adenoma & 9 & 2 & 11 & 1 & 1 & & 2 & 1 & & & 1 & \\
\hline Other & 17 & 13 & 30 & 3 & 2 & & 5 & 2 & & & 2 & \\
\hline Unspecified & 14 & 12 & 26 & 2 & & & 2 & & & & 1 & \\
\hline Histiocytosis & 14 & 8 & 22 & & & 1 & 3 & & & & & \\
\hline Septo-optic dysplasia & 11 & 16 & 27 & & & 1 & 4 & & & & & \\
\hline Other central nervous system lesion - for example, & & & & & & & & & & & & \\
\hline hydrocephalus, postmeningitis & 36 & 26 & 62 & & & 5 & 6 & & & 2 & & 5 \\
\hline Acute leukaemia or lymphoma & 17 & 6 & 23 & & & & 3 & & & & & \\
\hline Genetic short stature and growth delay, or both & 47 & 15 & 62 & & & & & & & 1 & & 2 \\
\hline Turner's syndrome & & 44 & 44 & & & 1 & 1 & & & 1 & & 1 \\
\hline Low birth weight or Silver's syndrome & 12 & 9 & 21 & & & & & & & & & 3 \\
\hline Other-for example, Prader-Willi syndrome & 15 & 16 & 31 & & & 2 & 3 & & & & & \\
\hline Total & 1246 & 662 & 1908 & 68 & & 42 & 110 & 6 & & 30 & & 98 \\
\hline
\end{tabular}


Osteosarcoma of the fibula (case 13) developed distant from the irradiation field (anterior and lateral beams to the pituitary area). One patient developed Hodgkin's lymphoma five years after hormone treatment, and one developed the myelodysplastic syndrome after eight years' treatment for isolated growth hormone deficiency; Fanconi's anaemia was then diagnosed. ${ }^{17}$

Follow up from diagnosis and initial management of patients with craniopharyngioma, including those identified after starting hormone treatment, ranged from 6 to 37 years (mean 17.3, SD 6.7, $\mathrm{n}=227$; missing $=5$ ). When the eight patients dying from other causes and the five (one death) with missing data were excluded 76 patients received radiotherapy during initial tumour management; eight of these died of tumour recurrence or complications. This number was not significantly different from the 18 deaths among 143 patients who did not receive early irradiation. Furthermore, there were proportionately no more deaths from craniopharyngioma (27 of 232) than other known intracranial primary tumours (24 of 202); the mean follow up from diagnosis and initial treatment of these tumours was 13.4 years (SD $4.9, n=200$; missing $=2$ ). Deaths from craniopharyngioma occurred at a mean of $10 \cdot 1$ years (SD 5.9; range $1-14$ ) after tumour diagnosis, which did not differ from the $7 \cdot 3$ years $(5 \cdot 1 ; 0 \cdot 5-20 ; 23 ; 1)$ for other intracranial tumours. Only $25 \%$ of patients with intracranial tumours began growth hormone within two years of diagnosis, whether this was a craniopharyngioma (mean interval $4 \cdot 1$ years, SD $3 \cdot 8, \mathrm{n}=226$; missing $=6$ ) or other tumour $(4 \cdot 0,3 \cdot 2,200 ; 2)$. These patients survived early complications and were likely to have a better prognosis.

Both patients who died of leukaemia had had a previous relapse. One relapsed within a year of starting growth hormone (previous central nervous system relapse twice and testicular once). The other began treatment four years after testicular relapse but relapsed again seven months later only to die in remission after bone marrow transplantation. Metastatic colonic carcinoma occurred in a boy with hypopituitarism who had had previous surgery for imperforate anus; his sister died of acute childhood leukaemia.

\section{HYPOPITUITARISM}

Thirteen deaths were attributed to hypopituitarism (table IV), including six of 11 deaths in children under six years (the others were from medulloblastoma, bronchiolitis, pulmonary fibrosis after nitrogen mustard chemotherapy for medulloblastoma, subdural haemorrhage, and prolonged convulsion in a child with septo-optic dysplasia). The three youngest patients with panhypopituitarism were identified by hypo- glycaemia in the neonatal period. Only the 15 year old was not established on glucocorticoid replacement treatment before starting growth hormone treatment aged 5 years. Gonadotrophin deficiency was suggested by hypospadias, and thyrotrophin and adrenocorticotrophin deficiency (with hypoglycaemic convulsions) developed within two years.

\section{CREUTZFELDT-JAKOB DISEASE}

The first of the deaths from Creutzfeldt-Jakob disease (table V) antedated this study and was extensively reported. ${ }^{56}$ The other cases' were ascertained before death, and all but the sixth have been confirmed by neuropathological findings of spongiform encephalopathy. All presented with clinical features typical of spongiform encephalopathy after pituitary hormone treatment ${ }^{18}$ : rapidly progressive cerebellar dysfunction, ataxia as an early feature (with or without myoclonus), followed by dementia and death within 12 months of onset.

Three patients (cases 2, 5, and 6) had neither had neurosurgery nor received donor blood products or tissues. No single batch of growth hormone was common to the six patients, but all received growth hormone prepared before column chromatography was introduced into the purification procedure. One patient (case 3) received only four batches of hormone and another (case 4) never received hormone prepared by the Raben method. ${ }^{2}$ Three (cases 2, 4, and 6) completed their treatment with recombinant growth hormone.

Other deaths from neuromuscular disorders occurred in two patients with primary neuromuscular disease and four with epilepsy who died during seizures without evidence of hypoglycaemia.

\section{OTHER CAUSES OF DEATH}

Among six patients who died from respiratory infection two had cardiorespiratory complications post partum (isolated growth hormone deficiency) or postoperatively (jejunal bypass for obesity associated with hypothalamic dysfunction). A girl with hydrocephalus died of recurrent bacterial meningitis. Other deaths included respiratory failure in Prader-Willi syndrome, aortic dissection in Turner's syndrome, asthma in a hypopituitary boy, and a 14 year old boy found hanged ("open" verdict at inquest). One death, 17 years after treatment for subfrontal neuroblastoma, remained unexplained.

\section{Discussion}

This is the largest reported study of mortality in growth hormone deficient patients receiving growth hormone treatment, although subgroups of this cohort

\begin{tabular}{|c|c|c|c|c|c|c|}
\hline Case & Sex & Tumour & $\begin{array}{c}\text { Age when } \\
\text { tumour } \\
\text { diagnosed } \\
\text { (years) }\end{array}$ & Indication for growth hormone treatment & $\begin{array}{c}\text { Time after } \\
\text { start of } \\
\text { growth } \\
\text { hormone } \\
\text { (years) }\end{array}$ & Outcome \\
\hline 1 & F & Pituitary ${ }^{\star}$ & 19 & Panhypopituitarism & 2 & Alive \\
\hline 2 & $\mathrm{~F}$ & Hypothalamic ${ }^{\star}$ & 14 & Growth hormone deficiency, diabetes insipidus & 2 & Alive \\
\hline 3 & $\mathrm{~F}$ & Third ventricle ${ }^{\star}$ & 12 & Growth hormone deficiency, diabetes insipidus & 2 & Alive \\
\hline 4 & $\mathrm{~F}$ & Germinoma of pituitary & 27 & Growth hormone deficiency, diabetes insipidus & 11 & Alive \\
\hline 5 & $\mathrm{~F}$ & Germinoma of fossa hypophysialis & 13 & Isolated growth hormone deficiency & 1 & Alive \\
\hline 6 & $\mathrm{~F}$ & Germinoma & 21 & Isolated growth hormone deficiency, delayed puberty & 6 & Alive \\
\hline 7 & $\mathbf{F}$ & Pinealoma & 19 & Short stature, delayed puberty & 2 & Alive \\
\hline 8 & $\mathbf{F}$ & Astrocytoma & 18 & Isolated growth hormone deficiency, temporal lobe epilepsy, tuberous sclerosis & 3 & Dead \\
\hline 9 & $M$ & Anaplastic astrocytoma & 19 & Isolated growth hormone deficiency & 3 & Dead \\
\hline 10 & M & Craniopharyngioma & 11 & Isolated growth hormone deficiency & 2 & Alive \\
\hline 11 & $\mathrm{M}$ & Anaplastic astrocytoma (1988) (medially right temporal lobe) & 21 & Craniopharyngioma (1982), 54 Gy cranial irradiation & 6 & Dead \\
\hline \multirow{2}{*}{12} & $M$ & Craniopharyngioma $\dagger$ & 18 & Panhypopituitarism & 1 & Alive \\
\hline & & Basal cell carcinoma (nose) & 25 & & 8 & \\
\hline 13 & $\mathrm{~F}$ & Osteosarcoma of fibula (1979) & 14 & Chromophobe adenoma (1974), 45 Gy cranial irradiation & 2 & Dead $\neq$ \\
\hline 14 & $\mathrm{M}$ & Hodgkin's lymphoma (lymphocyte depleted) & 25 & Isolated growth hormone deficiency & 10 & Alive \\
\hline 15 & $\mathrm{M}$ & Adenocarcinoma of transverse colon & 22 & Isolated growth hormone deficiency & 14 & Dead \\
\hline 16 & $M$ & Astrocytoma (1988) (left frontal region) & 17 & Acute lymphoblastic leukaemia, $35 \mathrm{~Gy}$ craniospinal irradiation & 3 & Dead \\
\hline
\end{tabular}




\begin{tabular}{llrc}
\hline Cause of death & \multicolumn{1}{c}{$\begin{array}{c}\text { Diagnosis } \\
\text { (years) }\end{array}$} & $\begin{array}{c}\text { Year of } \\
\text { death }\end{array}$ \\
\hline Hypoglycaemia & Panhypopituitarism & 3 & 1985 \\
Hypoglycaemia, cerebral infarction, infection & Septo-optic dysplasia & 3 & 1987 \\
Electrolyte disturbance & Panhypopituitarism & 4 & 1972 \\
Electrolyte disturbance, diabetes insipidus & Septo-optic dysplasia & 5 & 1979 \\
Gastroenteritis, diabetes insipidus & Craniopharyngioma & 5 & 1974 \\
Hypoglycaemia & Panhypopituitarism & 5 & 1986 \\
Epiglottiditis & Craniopharyngioma & 13 & 1985 \\
Bronchopneumonia, diabetes insipidus & Germinoma & 14 & 1985 \\
Adult respiratory distress syndrome, viral pneumonia, hypopituitarism & Panhypopituitarism & 15 & 1989 \\
Acute laryngotracheobronchitis, pneumonia & Glioma & 17 & 1987 \\
Respiratory infection, asthma, intracranial haemorrhage & Craniopharyngioma & 18 & 1973 \\
Bronchopneumonia, diabetes insipidus & Histiocytosis X & 18 & 1976 \\
Hypopituitarism & Panhypopituitarism & 57 & 1977 \\
\hline & & &
\end{tabular}

TABLE v-Clinical details of six patients dying from Creutzfeldt-Fakob disease after treatment with human pituitary growth hormone

\begin{tabular}{lcccc}
\hline Case & Sex & Diagnosis at start of treatment & $\begin{array}{c}\text { Period and duration } \\
\text { years) of pituitary growth } \\
\text { hormone treatment }\end{array}$ & $\begin{array}{c}\text { Date and age (years) } \\
\text { at death }\end{array}$ \\
\hline 1 & M & Craniopharyngioma (surgery 1964) & $1972-77(4 \cdot 5)$ & February 1985(22) \\
2 & M & Isolated growth hormone deficiency & $1974-85(9 \cdot 6)$ & April 1988(20) \\
3 & M & Craniopharyngioma (surgery 1968) & $1970-74(3 \cdot 0)$ & April 1990(34) \\
4 & M & Craniopharyngioma (surgery 1972) & $1976-85(9 \cdot 0)$ & April 1990(20) \\
5 & F & Isolated growth hormone deficiency & $1974-85(10 \cdot 9)$ & July 1990(20) \\
6 & M & Isolated growth hormone deficiency & $1975-85(10 \cdot 3)$ & December 1990 (21) \\
\hline
\end{tabular}

have been reported. ${ }^{19 \cdot 21}$ Half the deaths resulted from recognised brain tumours that were related to the growth hormone deficiency. Because of the patients' ages it was predictable that accidents and infection would be other main causes of death. ${ }^{22}$ This mortality pattern was found in growth hormone treated patients in France, although the mortality rate was one third of that in our study. ${ }^{23}$

The mortality findings for patients with craniopharyngioma were no better than for those with malignant intracranial tumours, representing late tumour recurrence for both groups. Deaths among patients with craniopharyngioma were apparently not reduced by early radiotherapy yet cranial irradiation may have contributed to two fatal second intracranial tumours. Children with tumours of the central nervous system seemed to have an increased risk of developing a second tumour in the central nervous system, ${ }^{24}$ and development of second tumours within radiotherapy fields after latencies such as the 6-10 years found by us has been reported..$^{25}$

Our study could not assess not-fatal tumour recurrences, and a control group not treated with growth hormone was not available. We cannot therefore conclude whether growth hormone contributed to tumour recurrence and death. Studies of subgroups of these patients showed no excess recurrence of commoner intracranial tumours compared with patients who had not received growth hormone ${ }^{1920}$; small studies suggest no increased risk of tumour recurrence. ${ }^{26} 27$

First intracranial tumours were identified in 10 patients with "idiopathic" growth hormone deficiency. These were probably causally related to the hormone deficiency but undetectable at the time. Improved imaging now permits earlier localisation of tumours although clinical features, such as epilepsy, delayed puberty, and diabetes insipidus, present in some of these cases, should alert doctors to the need for regular reassessment and long term follow up..$^{28} 29$

Deaths from hypopituitarism should be preventable. The risk of hypoglycaemia in young children, aggravated by acute infection, and the added complication of diabetes insipidus cannot be overemphasised. Education should minimise the risks of hypopituitary crises. The importance of periodic evaluation of pituitary function in growth hormone deficient patients is shown by the death of one boy whose panhypopituitarism evolved over several years. Morbidity associated with non-fatal metabolic disturbances due to hypopituitarism needs to be reviewed.

There have been recent reports of leukaemia developing after growth hormone treatment ${ }^{9 \cdot 14}$ but we identified no new cases of leukaemia; both instances of relapse were at high risk of further relapse. Of four extracranial malignancies two were second primary tumours (osteosarcoma and basal cell carcinoma). The first (reported previously as osteosarcoma of the femur ${ }^{25}$ ) had only cranial irradiation and neither had chemotherapy. Without a control group it is impossible to assess the relevance of growth hormone deficiency or treatment to increased risk of tumour formation. Short stature is associated with conditions with increased risk of malignancy and such patients have received growth hormone. These conditions include Fanconi's anaemia (two patients died from narrow aplasia and infection), neurofibromatosis, Bloom syndrome, Kearns-Sayre syndrome, and bilateral retinoblastoma. These patients should be monitored with particular care for tumour development.

World wide there have now been 16 cases of Creutzfeldt-Jakob disease after pituitary growth hormone treatment, the incidence among pituitary growth hormone recipients in the United States being similar to that in the United Kingdom (P Brown and J-C Job, personal communications). Additionally, two cases of the disease have occurred after treatment in Australia with extracted pituitary gonadotrophins (A Harding, personal communication ${ }^{30}$ ). Although the feared "epidemic" of this disease ${ }^{8}$ has not yet occurred, the rising number of cases suggests that people should remain alert to public health implications; transmission of Creutzfeldt-Jakob disease may occur through donor tissue, infected blood, and urine. ' Four patients with the disease in the United Kingdom received hormone concurrently in 1974, all six having treatment between 1974 and 1976, when about 400 patients were undergoing treatment in the United Kingdom. As no single hormone batch was common to these six patients, multiple contaminations with the infective agent must have occurred. One case of the disease in the United States was subclinical, diagnosed on review of necropsy tissue. ${ }^{31}$ Only $40 \%$ of patients who died in our study underwent necropsy, and evidence of the disease may have been missed. All patients treated with pituitary growth hormone have a small but presently undefined risk of developing Creutzfeldt-Jakob disease, and general practitioners and neurologists need to be aware of this possibility. Pathologists should heed precautions advised in these cases, ${ }^{32}$ and expert neuropathological studies of all future deaths among these patients are necessary.

The oldest surviving patient treated with pituitary growth hormone is only 47 years old. Lifelong surveillance of these patients is essential to assess fully both the benefits and possible adverse consequences of their treatment.

We thank the physicians who provided clinical details of their patients, particularly Dr C M C Allen, Dr H Besterman, Professor H S Jacobs, Dr P Kennedy, and Dr A B Kurtz; Dr Janice Anderson, Professor L W Duchen, and Professor $\mathrm{R} \mathrm{O}$ Weller for the neuropathological findings in cases of Creutzfeldt-Jakob disease; the Health Services Human Growth Hormone Committee; Miss Joanne Nash and Miss Carole Lawrence for their help in collating the data. This study was funded by the Department of Health.

\footnotetext{
1 Raben $M$. Treatment of a pituitary dwarf with human growth hormone. $\mathcal{F}$ Clin Endocrinol Metab 1958;18:901-3.

2 Milner RDG, Russell-Fraser T, Brook CGD, et al. Experience with human growth hormone in Great Britain: the report of the MRC working party Clin Endocrinol (Oxf) 1979;11:15-38.
} 
3 Buchanan CR, Law CM, Milner RDG. Growth hormone in short, slowly growing children and those with Turner's syndrome. Arch Dis Child 1987;62:912-6.

4 Preece MA. Experience of treatment with pituitary derived growth hormone with special reference to immunological aspects. In: Milner RDG, Flodh $\mathrm{H}$ with special reference to immunological aspects. In: Milner RDG, Flodh $\mathrm{H}$,
eds. Immunological aspects of human growth hormone. Oxford: Medical eds. Immunological aspects of

5 Powell-Jackson J, Weller RO, Kennedy P, et al. Creutzfeldt-Jakob disease after administration of human growth hormone. Lancet 1985;ii:244-6.

6 Weller RO, Steart PV, Powell-Jackson JD. Pathology of Creutzfeldt-Jakob disease associated with pituitary-derived human growth hormone administration. Neuropathol Appl Neurobiol 1986;12:117-29.

7 Preece MA. Creutzfeldt-Jakob disease: implications for growth hormone deficient children. Neuropathol Appl Neurobiol 1986;12:509-15.

8 Brown PB, Gajdusek C, Gibbs CJ, Asher DM. Potential epidemic of Creutzfeldt-Jakob disease from human growth hormone therapy. $N$ Engl f Med 1985;313:728-30.

9 Watanabe S, Tsunematsu Y, Fujimoto J, Komiyama A. Leukaemia in patients treated with growth hormone. Lancet 1988;i:1159.

10 Delemarre-Van de Waal HA, Odink JH, de Grauw TJ, de Waal FC. Leukaemia in patients treated with growth hormone. Lancet 1988; i:1159.

11 Fisher DA, Job J-C, Preece MA, Underwood LE. Leukaemia in patients treated with growth hormone. Lancet 1988;i:1159-60.

12 Frisch $\mathrm{H}$, Thun-Hoenstein L, Balzar E. Leukaemia and growth hormone. Lancet 1988;i:1335.

13 Redman GP, Shu S, Norris D. Leukaemia and growth hormone. Lance 1988;i:1335.

14 Stahnke N, Zeisel HJ. Growth hormone therapy and leukaemia. Eur $\mathcal{F}$ Pediatr 1989;148:591-6.

15 Milner RDG, Barnes ND, Buckler JMH, et al. United Kingdom multicentre clinical trial of somatrem. Arch Dis Child 1987;62:776-9.

16 Tanner JM, Whitehouse RH, Hughes PCR, Vince FP. Effect of human growth hormone treatment for 1 to 7 years on growth of 100 children with growth hormone deficiency, low birth weight, inherited smallness, Turner's syndrome and other complaints. Arch Dis Child 1971;46:745-82.

17 Standen GR, Hughes IA, Geddes D, Jones BM, Wardrop CAJ. Myelodysplastic syndrome with trisomy 8 in an adolescent with Fanconi anaemia and plastic syndrome with trisomy 8 in an adolescent with
selective IgA deficiency. Am $\mathcal{F}$ Hematol 1989;31:280-3.

18 Brown PB. The decline and fall of Creutzfeldt-Jakob disease associated with human growth hormone therapy. Neurology 1988;38:1135-7.
19 Clayton PE, Shalet SM, Gattamaneni HR, Price DA. Does growth hormone cause relapse of brain tumours. Lancet 1987;i:711-3.

20 Clayton PE, Price DA, Shalet SM, Gattamaneni HR. Craniopharyngioma recurrence and growth hormone therapy. Lancet 1988; ; 642 .

21 Whitehead HM, Hadden DR, Carson DJ. The Northern Ireland experience of growth hormone therapy for short stature. Ulster Med f 1989;58:153-60.

22 Office of Population Censuses and Surveys. Mortality statistics. Review of the registrar general on deaths by cause, sex and age in England and Wales. London: HMSO, 1988. (Series DH2 1986.)

23 Goujard J, Entat M, Maillard F, et al. Human pituitary growth hormone (hGH) and Creutzfeldt-Jakob disease: results of an epidemiological survey in France, 1986. Int f Epidemiol 1988;17:423-7.

24 Farwell J, Flannery JT. Second primaries in children with central nervous system tumours. $\mathcal{F}$ Neurooncol 1984;2:371-5.

25 Kingston JE, Hawkins MM, Draper GJ, Marsden HB, Wilson LMK. Pattern of multiple primary tumours in patients treated for cancer during childhood. Brf Cancer 1987;56:331-8.

26 Arslanian SA, Becker DJ, Lee PA, Drash LA, Foley TP. Growth hormone and tumor recurrence. Findings in children with brain neoplasms and hypopituitarism. Am f Dis Child 1985;139:347-50.

27 Rodens KP, Kaplan SL, Grumbach MM, Teller WM. Does growth hormone therapy increase the frequency of tumor recurrence in children with brain therapy increase the frequency of tumor recurrence in ch
tumors? Acta Endocrinol (Copenh) 1987;283(suppl): 188-9.

28 Sherwood MC, Stanhope R, Preece MA, Grant DB. Diabetes insipidus and occult intracranial tumours. Arch Dis Child 1986;61:1222-5.

29 Stanhope R, Preece MA, Brook CGD, Grant DB. Is diabetes insipidus during childhood ever idiopathic? Brf Hosp Med 1989;41:490-1.

30 Cochius JI, Mack K, Burns RJ, Alderman CP, Blumbergs PC. CreutzeldtJakob disease in a recipient of human pituitary-derived gonadotrophin. Aust NZ J Med 1990;20:592-3.

31 New MI, Brown P, Temeck JW, et al. Preclinical Creutzfeldt-Jakob disease discovered at autopsy in a human growth hormone recipient. Neurology 1988;38:1133-4.

32 Committee on Health Care Issues, American Neurological Association. Precautions in handling tissues, fluids, and other contaminated materials from patients with documented or suspected Creutzfeldt-Jakob disease. Ann Neurol 1986;19:75-7.

(Accepted 10 fanuary 1991)

\section{Coppetts Wood Unit, \\ Royal Free Hospital Department of Infectious and Tropical Diseases,} London N10

M G Jacobs, MB, senior house officer

M G Brook, MD, senior registrar

W R C Weir, MRCP, consultant physician

B A Bannister, FRCP,

consultant physician

Correspondence and requests for reprints to: Dr Brook.

BMF 1991;302:828-9

\section{Dengue haemorrhagic fever: a risk of returning home}

\author{
M G Jacobs, M G Brook, W R C Weir, \\ B A Bannister
}

The number of imported cases of infection with dengue virus each year is rising as a consequence of increased travel and an increase in the worldwide incidence of dengue. ${ }^{1}$ Almost all travellers who become infected with the virus experience a benign, if uncomfortable, febrile illness. We report on two adult residents of the United Kingdom who visited their country of origin and developed a severe, life threatening complication of this infection known as dengue haemorrhagic fever.

\section{Case reports}

Case 1-A 73 year old Malaysian woman had been living in the United Kingdom for many years. She spent two months visiting Malaysia and on her return complained of unremitting fever, anorexia, and nausea. By the fourth day she had developed nose bleeds, haemoptysis, haematuria, and a generalised petechial rash. Tests showed severe thrombocytopenia (platelet count $3 \times 10^{9} / 1$ ) with a low white cell count (total white cells $1.6 \times 10^{9} / 1$; neutrophils $0.48 \times 10^{9} / 1$ ) and haemoglobin concentration $(86 \mathrm{~g} / \mathrm{l})$. Virus related haemophagocytic syndrome was diagnosed on bone marrow aspiration. ${ }^{2}$ Management consisted of treatment with broad spectrum antibiotics appropriate for neutropenia and platelet transfusions. She made an uneventful recovery. Infection with dengue virus was diagnosed by an eightfold rise in antibody titres.

Case 2-A 41 year old Pakistani man returned to the United Kingdom, where he had been living for many years, after a two week visit to Pakistan. He developed a confluent petechial rash after six days of fever, nausea, diarrhoea, and headache. Tests showed thrombocytopenia (platelet count $18 \times 10^{\circ} / 1$ ) and a severe coagulopathy (partial thromboplastin time $66 \mathrm{~s}$; thrombin time $>120 \mathrm{~s}$ ). He was treated with blood products and made an uneventful recovery. Infection with dengue virus was diagnosed by an eightfold rise in antibody titres.

\section{Comment}

Dengue viruses, comprising four distinct serotypes of flavivirus, are transmitted from infected to susceptible humans by Aedes mosquitoes. This vector is ubiquitous in the tropics, where dengue is a major public health problem. The first infection with dengue virus, usually in early childhood, may pass unrecognised or cause a self limiting febrile illness. This is followed by lifelong homotypic immunity, but after a few months of cross protection the subject is susceptible to infection with other serotypes. Considerable evidence suggests that haemorrhagic complications are associated with subsequent infection with a second serotype. This explains an early observation that foreign visitors who have not been exposed to dengue virus previously develop uncomplicated dengue during outbreaks of dengue haemorrhagic fever among indigenous people. ${ }^{+}$It is believed that "immune enhancement" of viral replication underlies the development of severe, haemorrhagic disease: non-neutralising, cross reacting antibodies opsonise virus of a second serotype and enhance uptake into mononuclear phagocytes, in which the virus replicates. ${ }^{5}$

Large epidemics of dengue haemorrhagic fever among children are frequently reported in the tropics, particularly in South East Asia and the Caribbean, with an associated mortality of $2-10 \%$. This syndrome is rare in adults and has not, we believe, been reported before in travellers returning to the United Kingdom. We presume that our patients acquired dengue haemorrhagic fever as a result of infection with a second serotype of dengue virus after a delay of many years since their first exposure to the virus. This potential problem should be remembered whenever people return to the tropics, and they should be 